\title{
OCCLUSION OF A PRE-RETINAL ARTERIAL LOOP*†
}

\section{BY}

\author{
R. B. HARCOURT AND N. A. LOCKET \\ Moorfields Eye Hospital, London
}

A CONGENITAL vascular anomaly in which one of the main branches of the central retinal artery forms a pre-retinal loop at the optic disc before being distributed in the normal manner has been described by several authors (Liebreich, 1871; Leber, 1915; Bisland, 1953). The condition is usually first noticed on routine examination of an otherwise normal fundus, and remains symptomless throughout life. Very rarely, however, it may be discovered following occlusion of the affected vessel.

\section{Case Report}

A 22-year-old woman was seen on March 11, 1965, in the Casualty Department of Moorfields Eye Hospital, High Holborn. She gave a history that while out walking 6 hours previously she had suffered a sudden complete loss of the upper half of the left visual field, with no premonitory symptoms.

Examination.-Visual acuity of $6 / 5$ in the right eye and $6 / 6$ in the left eye was not improved by correction of a trivial refractive error. The eyes were normal apart from bilateral retinal arterial anomalies. In the right eye (Fig. 1) the inferior division of the central retinal artery formed a small simple pre-retinal loop, passing first forwards from the optic disc and then backwards again before being distributed to the inferior half of the retina in the normal manner. Both limbs of this loop were filled with blood, and the vessel was of normal calibre throughout its course. The visual field was full.

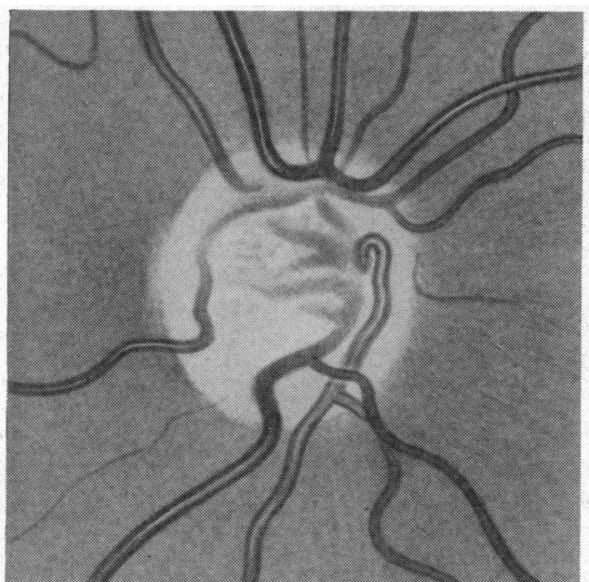

FIG. 1.-Right optic disc, showing short patent simple pre-retinal loop in inferior division of central retinal artery.

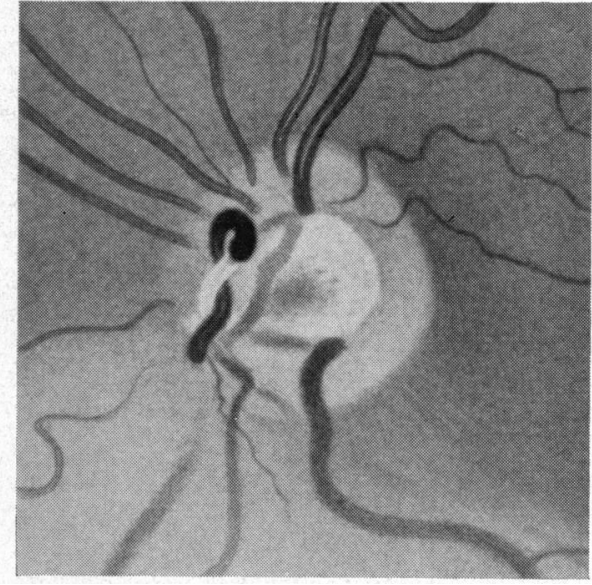

Fig. 2.-Left optic disc with long spiral preretinal loop in the course of the inferior division of the central retinal artery, the blood column being interrupted near the apex of the loop.

In the left eye the inferior division of the central retinal artery exhibited a similar but much longer spiral pre-retinal loop at the optic disc. The proximal limb of the loop as far as the apex was of normal calibre and filled with blood. The distal portion, passing back towards the disc, was transparent and empty (Fig. 2).

* Received for publication April 18, 1966.

$\dagger$ Address for reprints: Moorfields Eye Hospital, High Holborn, London, W.C.1. 
The inferior temporal and inferior nasal arterial branches and their tributaries were all markedly attenuated, and considerable diffuse oedema was present in these lower retinal quadrants (Fig. 3).

FIG. 3.-General view of left fundus shortly after vascular accident, showing retinal oedema in area of distribution of occluded inferior division of central retinal artery.

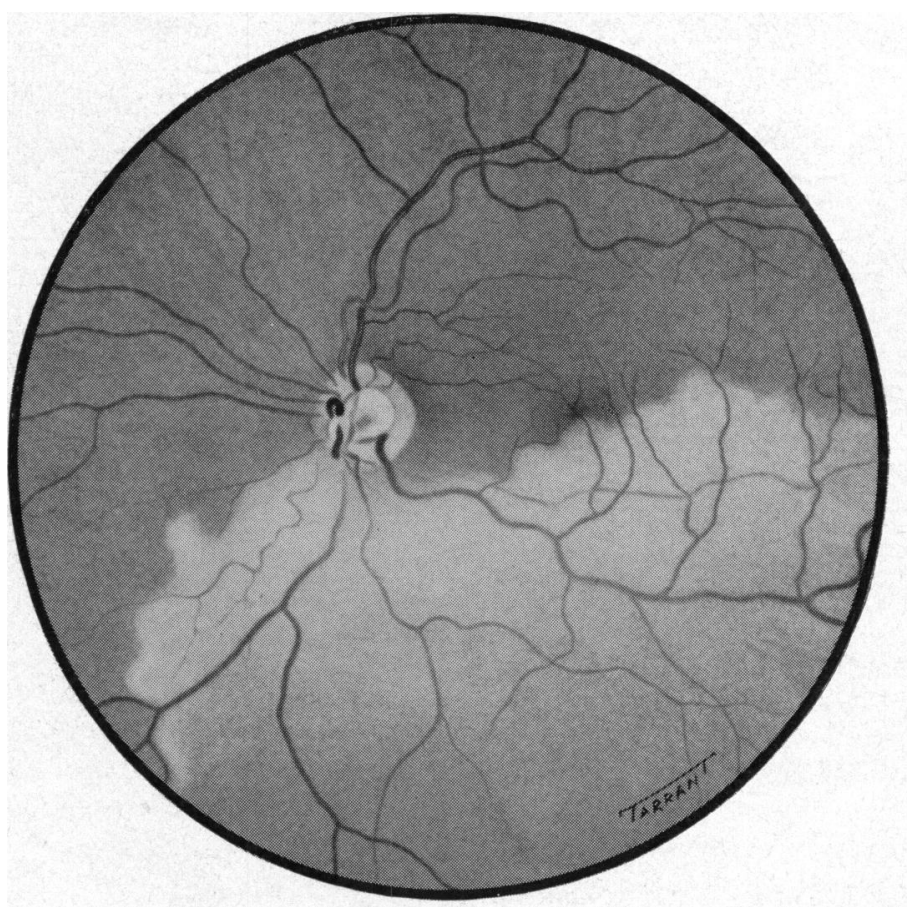

There was almost complete loss of the upper half of the visual field to a $3 / 330$ white target (Fig. 4).

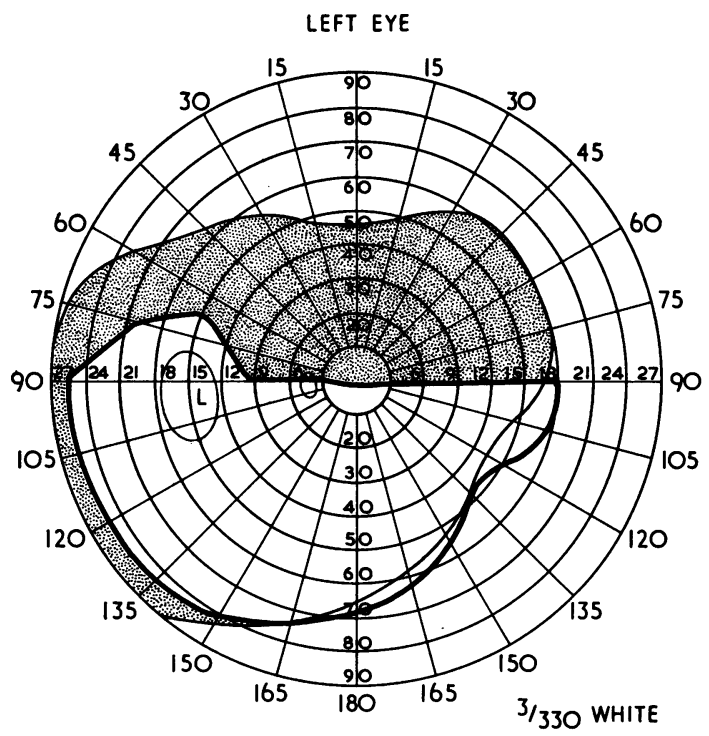

FIG. 4.-Left peripheral visual field charted on March 3, 1965, shortly after onset of symptoms.

A complete general medical examination revealed no abnormality; haematological and urinary investigations also gave negative results. 
Treatment.-The patient was given a left retrobulbar injection of $25 \mathrm{mg}$. Priscol, and admitted to hospital.

Progress.- No early change was observed in the appearance of the left fundus, but 2 days after the onset of symptoms the distal limb of the spiral pre-retinal loop was noted to have refilled with blood. The vascular attenuation gradually diminished, and the retinal oedema subsided completely in 5 weeks, by which time the visual acuity had improved to 6/5, although there was no recovery of visual field loss. Since that time the fundus appearances and the field defect have remained unchanged, and there have been no further episodes of loss of vision.

\section{Discussion}

Mann (1957) described pre-retinal arterial vascular loops of various types. These are either simple or spiral; the proximal limb invariably arises and passes forward from the optic disc, but the distal limb may either return to the disc or pass peripherally to be distributed in the manner of a normal retinal arterial branch. Embryologically they are formed as looped branches of the developing central retinal artery within Bergmeister's papilla, and are not part of the foetal hyaloid vascular system. As the glial cone atrophies, the loop is left projecting forwards from the plane of the disc and retina. Bisland (1953), reviewing the whole literature, found 58 recorded cases of vascular loops, four-fifths of which were arterial, and he added five new cases, but as these abnormal vessels usually give rise to no symptoms throughout life they are probably much more common than this (Duke-Elder, 1964). It is rare, however, for these loops to be the site of arterial occlusion and there are only two previously recorded cases (Bär, 1901; Walker, 1903).

The first case was that of an elderly patient who exhibited the sequelae of inferior branch retinal artery occlusion, with visual acuity of counting fingers in the affected eye, a pale disc, attenuated inferior retinal vessels, and a permanent upper field defect. The second case was that of a 22-year-old healthy male who was seen shortly after the sudden loss of the upper half of one visual field; inferior retinal oedema was found which subsided leaving a permanent upper field defect.

In both these previous cases a long spiral arterial loop was found extending forwards from the optic disc in the affected eye, but in each case both limbs of the abnormal loop were reported as being filled with blood, whereas in the present case the site of the temporary arterial occlusion could be clearly seen at the apex of the spiral loop.

Theoretically there are several ways in which an occlusion may occur at such a site. It may be caused by an embolus, but in this case no embolus was visible within the affected vessel on ophthalmoscopic examination and there was no evidence of any systemic disease likely to give rise to emboli. It may be due to localized sclerotic changes in the vessel wall at the apex of the loop, caused by the abnormal haemodynamics of rapid high pressure blood flow around this acutely angled bend, which ultimately obliterate the lumen of the vessel. Such an occlusion would be permanent, and the temporary nature of the occlusion found in this case is against such a concept. Temporary occlusion may be caused by kinking of the vascular loop, just as kinking of the bowel may cause intestinal obstruction, and it seems reasonable to suggest that this was the obstructive mechanism in the present case, 
for such an occurrence would be more likely in a long spiral loop where the angulation of the vessel at the apex is particularly acute, and in each of the three cases of vascular occlusion described the loop was of this type.

\section{Summary}

A case is described in which a spiral pre-retinal arterial loop was the site of a temporary retinal artery branch occlusion in an otherwise healthy young patient. The possible mechanism of the occlusion is discussed, and the only other similar reports in the literature are briefly referred to.

We wish to thank Mr. Stephen Miller, under whose care the patient was admitted, for permission to publish this case, and the Medical Illustration Department of the Institute of Ophthalmology for the preparation of the fundus paintings.

\section{REFERENCES}

Bär, C. (1901). Klin. Mbl. Augenheilk., 39, 307.

Bisland, T. (1953). Arch. Ophthal. (Chicago), 49, 514.

Duke-Elder, S. (1964). "System of Ophthalmology", vol. 3, part 2, p. $786 . \quad$ Kimpton, London.

Leber, T. (1915). "Graefe-Saemisch-Hess Handbuch der gesamten Augenheilkunde", 2nd ed., band 7A, teil 2, Kap. X A, 1. Hälfte, p. 1. Engelmann, Leipzig.

Liebreich, T. (1871). Trans. path. Soc. Lond., 22, 221.

ManN, I. (1957). "Developmental Abnormalities of the Eye", 2nd ed., p. 133. B.M.A., London.

WALKer, C. H. (1903). Trans. ophthal. Soc. U.K., 23, 279. 